\title{
Efeitos dos investimentos em infraestrutura pública sobre a pobreza e pobreza extrema na América Latina
}

\section{Effects of investments in public infrastructure on poverty and extreme poverty in Latin America}

\author{
Anibal David Cuenca López* \\ Evandro Camargos TeiXeira*
}

\begin{abstract}
This study aims to analyze the effect of investments in infrastructure, particularly economic and social, on poverty in Latin America. For this purpose, dynamic panel data is used for 15 countries corresponding to the period 1996-2016. Two models were estimated, one for poverty and the other for extreme poverty, in order to compare the effects of infrastructure on different indicators. The results revealed that the infrastructure has a significant impact on the selected indicators, especially on extreme poverty. Thus, it is recommended that governments emphasize the implementation of infrastructure projects as a fundamental tool for poverty and indigence reduction.
\end{abstract}

Keywords: infrastructure, poverty, extreme poverty, dynamic panel, Latin America.

\begin{abstract}
Resumo
Este estudo tem como objetivo analisar o efeito dos investimentos em infraestrutura, particularmente econômica e social, sobre a pobreza na América Latina. Para tal, utilizam-se dados em painel dinâmico para 15 países correspondentes ao período 1996-2016. Foram estimados dois modelos, um para a pobreza e outro para pobreza extrema, com o intuito de comparar os efeitos da infraestrutura sobre diferentes indicadores. Os resultados revelaram que a infraestrutura impacta significativamente sobre os indicadores selecionados, principalmente sobre a pobreza extrema. Assim, recomenda-se que os governos enfatizem a implementação de projetos de infraestrutura como uma ferramenta fundamental para redução da pobreza e indigência.
\end{abstract}

Palavras-chave: infraestrutura, pobreza, pobreza extrema, painel dinâmico, América Latina.

*Universidade Federal de Viçosa, correo-e: acuenca0591@gmail.com y evandro.camargos@ 


\section{Introduçáo}

A pobreza é uma condição socioeconômica de natureza complexa, multidimensional, que limita o bem-estar dos indivíduos e consequentemente o desenvolvimento econômico dos países. Em geral, são considerados pobres os indivíduos, famílias e grupos de pessoas, cujos recursos monetários são inferiores a uma linha de rendimento que lhes permita manter um padrão de vida decente. Nesse sentido, o rendimento monetário, geralmente, é a única variável utilizada para medir o nível de pobreza, também conhecido como pobreza absoluta (García et al., 2016).

Levando esse aspecto em consideração, segundo a Comissão Econômica para a América Latina e o Caribe (CEPAL, 2018a), a pobreza consiste na insuficiência de recursos monetários para alcançar um nível de qualidade de vida adequado que permita satisfazer as múltiplas necessidades humanas, como acesso aos serviços básicos, proteção social adequada, assim como maior participação social.

Níveis elevados de pobreza, geralmente, estão relacionados a desigual distribuição de renda, além de escassez de investimentos e inovaçōes, caracterizando um panorama de dificuldades em termos de desenvolvimento econômico. Logo, a superação da pobreza é um fator fundamental para que os países possam mudar seu patamar em termos de desenvolvimento e o investimento em infraestrutura pública é primordial, o que é denotado nos Objetivos de Desenvolvimento Sustentável (ODS) das Nações Unidas (ONU).

Em geral, a infraestrutura corresponde a um conjunto de estruturas de engenharia, equipamentos e instalaçóes de longa vida útil, que permitem a prestação de serviços para os setores produtivos e famílias (Perroti e Sánchez, 2012). Segundo o Banco Mundial (1994), a infraestrutura de forma geral pode incluir diferentes atividades de serviços públicos, tais como eletricidade, telecomunicaçóes, abastecimento de água e esgoto, eliminação de resíduos sólidos, obras públicas -estradas, construção de barragens, canais de irrigação e drenagem-e outros setores dos transportes, tais como ferrovias urbanas e interurbanas, transporte urbano, portos, hidrovias e aeroportos.

Diante da elevada quantidade de elementos proxies de infraestrutura, Torrisi (2009) classifica seus investimentos em econômico e social. O primeiro eleva a produtividade de forma direta e indireta, através das estradas, rodovias, aeroportos, transporte naval, redes de esgotos, aquedutos, redes de distribuição de água, energia e gás, estaçôes de irrigação e estruturas dedicadas à transferência de produtos. Por outro lado, os investimentos em infraestrutura social são aqueles destinados a aumentar o conforto social e atuar sobre a produtividade econômica, direcionados às 
escolas, segurança pública, usinas de eliminação de resíduos, hospitais, estruturas esportivas, áreas verdes, etc.

A junção de investimentos públicos em infraestrutura econômica e social é fundamental para aumentar as oportunidades e consequentemente diminuir as desigualdades e pobreza. Assim, para reduzir o nível de pobreza em qualquer país é necessário que o crescimento econômico alcance toda população, principalmente através da geração de empregos (Araújo et al., 2014).

Indo ao encontro dessa ideia, Durán e Saavedra (2014) salientam que a infraestrutura é capaz de reduzir a pobreza de duas formas: efeitos diretos ou de curto prazo e efeitos indiretos de médio e longo prazos. Os referidos efeitos têm sido elevados na América Latina nas últimas décadas, mas não foram suficientes para atender as necessidades em termos de quantidade e qualidade necessárias, particularmente quando comparados com o panorama das economias do sudeste asiático.

De acordo com estimativas da Comissão Econômica para a América Latina e o Caribe (CEPAL), para atender a lacuna existente entre oferta e demanda por infraestrutura na região, os países devem investir $6.2 \%$ do seu Produto Interno Bruto anual (PIB) entre 2012 e 2020. Tais investimentos devem priorizar obras ligadas aos setores de transporte, energia, telecomunicaçóes, água e saneamento, o que aumentaria o bem-estar geral da população (Perroti e Sánchez, 2012).

Nesse contexto, diante do quadro descrito, o objetivo desse estudo é analisar a relação existente entre os investimentos em infraestrutura pública, particularmente econômica e social, sobre a pobreza e extrema pobreza na América Latina. Para atingir o referido objetivo, utiliza-se um modelo de dados em painel dinâmico de 15 países da região para o período 1996-2016, estimado pelo método generalizado de momentos (GMM), desenvolvido por Arellano e Bond (1991), Arellano e Bover (1995) e Blundell e Bond (1998).

Diante da literatura concernente ao tema, a ser apresentada na próxima seção, a principal contribuição deste trabalho consiste em analisar e comparar os efeitos sobre a pobreza dos dois tipos de infraestrutura pública considerados: econômica e social. Importante salientar que se leva em consideração indicadores de pobreza na América Latina medidos através da linha de pobreza monetária (linha de pobreza e extrema pobreza). Nesse sentido, a população que vive com menos de USD 3,20 por dia é considerada pobre, e aquela que vive com menos de USD 1,90 por dia é considerada pobre extrema.

Para atingir os objetivos traçados, o estudo divide-se em seis seçóes, incluindo a introdução. A seguinte seção apresenta uma contextualização histórica e política dos investimentos em infraestrutura durante o período 
analisado na América Latina. Em seguida, são apresentados aspectos teóricos e empíricos, que enfatizam a relação entre infraestrutura e pobreza. Posteriormente, é apresentada a seção metodológica e logo depois os resultados. Por fim, são apresentadas as considerações finais.

\section{Contextualizaçáo histórica e política dos investimentos em infraestrutura na América Latina}

Para melhor compreender os efeitos dos investimentos em infraestrutura sobre a pobreza e extrema pobreza na América Latina, objeto do presente estudo, esta seção contextualiza histórica e politicamente o comportamento dos primeiros.

Na década de 1950, os países da América Latina implementaram a estratégia nacional-desenvolvimentista baseada na teoria econômica estruturalista e de desenvolvimento. Este modelo, denominado Industrialização por Substituição de Importações, obteve efeitos positivos ao estabelecer uma base industrial para os países da regiảo. Entretanto, após a crise da dívida externa combinada com elevadas taxas de inflação nos anos 1970 e início de 1980, chegou ao fim esta etapa (Bresser-Pereira, 2010; Rego, 2014). A crise causou graves problemas financeiros na região, o que afetou o processo produtivo, além dos investimentos em infraestrutura (Rego, 2014; Serebrisky et al., 2015).

No final da década de 1980, o modelo desenvolvimentista foi substituído pela execução de políticas macroeconômicas estabelecidas no Consenso de Washington, cujas estratégias se baseavam principalmente na desregulamentação dos mercados, crescimento com poupança externa, taxas de juros elevadas e câmbio sobrevalorizado. No entanto, em função das crises financeiras do México em 1994, asiática em 1997, russa em 1998, da Argentina em 2001 e com os consequentes déficits nos balanços de pagamentos, evidenciou-se o fracasso dessa estratégia (Bresser-Pereira, 2010).

O referido fracasso das políticas macroeconômicas teve como consequência a diminuição dos investimentos públicos a partir de 1987, gerada principalmente pela redução da despesa pública, além do aumento do investimento privado, que pretendia compensar a redução do investimento público em infraestrutura. Assim, no ano de 1990 os investimentos públicos em infraestrutura diminuíram, caindo para $30 \%$ e permaneceram estáveis até meados da década de 2000. A partir de 2005, a composição do investimento público mudou a favor da infraestrutura, o que aumentou sua participaçáo no investimento público total para $50 \%$. Consequentemente, houve acréscimo no estoque de infraestrutura, contribuindo no 
processo de crescimento econômico da América Latina e Caribe (ALC) (Serebrisky et al., 2015).

No entanto, os investimentos públicos na América Latina registraram crescimento moderado em relação ao PIB nos últimos anos. No período 2011 e 2014, a taxa média anual de investimentos públicos foi de $1.5 \%$ do PIB de cada país. Por outro lado, no que concerne os investimentos privados a dinâmica foi diferente, com tendência crescente (Kogan e Bondorevsky, 2016). Entre 1990 e 2013, o setor privado investiu na ALC cerca de 30\% mais que nas economias asiáticas desenvolvidas e cinco vezes mais que na África subsaariana. Porém, o aumento dos investimentos privados não foi suficiente para compensar a queda abrupta dos investimentos públicos (Serebrisky et al., 2015).

Assim, pode-se concluir que mesmo com o recente avanço, segundo o Relatório apresentado pelo Banco Interamericano de Desenvolvimento (BID), a ALC não tem investido o suficiente em infraestrutura, dado que a média anual de investimentos nessa cifra foi de $2.4 \%$ entre 1992 e 2013. Como prova disso, os investimentos em infraestrutura na ALC resultam em $0.8 \%$ menos do PIB que nos Estados Unidos ou na União Europeia, regióes com dotaçóes de capitais muito mais elevadas, que centram a maior parte dos seus investimentos na manutenção da infraestrutura. Somente a Nicarágua ultrapassou o limiar de 5\% do PIB entre 2008 e 2013; no entanto, nenhuma das principais economias da regiāo (Argentina, Brasil, Chile e México) investiu mais de 3\% do PIB, distante dos 5\% recomendados para diminuir o hiato existente.

Desse modo, a lacuna em termos de infraestrutura continua elevada na região. Em 2015, mais de 23 milhóes de pessoas não tinham acesso a água e saneamento de qualidade. Além disso, a cobertura da rede rodoviária na América Latina é limitada e por isso está na quarta posição em termos de desempenho logístico mundial. Cabe ainda salientar que em 2014 mais de 18 milhôes de indivíduos não tiveram acesso à energia elétrica e no setor das telecomunicações, a tecnologia acessível é baixa. Importante ainda salientar que a cobertura médica ainda é limitada e muitos indivíduos não têm acesso a serviços de saúde de qualidade. Finalmente, no que diz respeito a educação, as taxas de matrícula e graduação de alunos em comparação aos países desenvolvidos são extremamente baixas (Cuenca-López e Torres, 2020).

\section{Aspectos teóricos e empíricos}

A pobreza é um fenômeno amplamente estudado na literatura. Segundo Crespo e Gurovitz (2002), o conceito de pobreza pode ser operacionalizado 
sem levar em consideração 'juízo de valor' em termos relativos ou absolutos. Nesse sentido, pobreza relativa é relacionada com a desigualdade na distribuição de renda, ou seja, se o indivíduo está situado em um intervalo inferior da distribuição. Por outro lado, a pobreza absoluta ou extrema é determinada através da porcentagem da população que não é capaz de satisfazer suas necessidades nutricionais, de moradia, de vestuário, entre outras; sendo calculada através do rendimento mínimo para adquirir os diferentes itens.

A referida classificação do fenômeno da pobreza é fruto dos esforços e estudos liderados pelos organismos internacionais, como ONU, Banco Mundial, CEPAL, entre outros. O principal objetivo é unir forças no intuito de diminuir a pobreza, relativa e extrema. Durante o processo de discussão entre os organismos internacionais, a melhoria da infraestrutura sempre foi considerada uma medida extremamente eficaz.

Nesse sentido, a infraestrutura pública de qualidade permite aos indivíduos de forma direta o acesso a serviços de educação e saúde, além de facilitar o acesso à água potável e energia, por exemplo. Além disso, indiretamente, ela é capaz de elevar o nível de produtividade, reduzir custos de transporte, gerar empregos, entre outros efeitos (Sánchez et al., 2017).

Diante da mencionada importância, vários estudos existentes na literatura enfatizam a importância do impacto da infraestrutura sobre o nível de pobreza. A maioria dos estudos denota que a oferta de infraestrutura pública de qualidade é fator-chave para redução da pobreza. O mecanismo que ilustra o referido efeito se dá pela elevação dos gastos governamentais, que aumentam a demanda por trabalho e os salários à medida que a economia cresce e se torna mais eficiente e competitiva (Araújo et al., 2014). Para ilustrar os trabalhos que analisam a relaçáo supracitada de forma geral e estudando a realidade de Bangladesh, Raihan (2011) afirma que os investimentos em infraestrutura são determinantes no processo de crescimento econômico e alívio da pobreza.

A literatura denota ainda que a relação entre infraestrutura e pobreza ocorre tanto no meio rural quanto urbano. Nesse sentido, Ali e Pernia (2003) consideraram informaçóes de diversos estudos que relacionam infraestrutura e pobreza nos países asiáticos. Os autores concluíram que os investimentos em infraestrutura no meio rural elevam a produtividade agrícola e o emprego, gerando crescimento econômico mais rápido nos países em desenvolvimento e dessa forma reduzindo a pobreza. Além disso, os autores ressaltam que o impacto marginal da infraestrutura de energia sobre a pobreza diminui ao longo do tempo. Por outro lado, os investimentos em estradas possuem fortes efeitos diretos e indiretos na 
redução da pobreza, sendo seus impactos mais elevados quando combinados com outros complementares, como em capital humano.

Por sua vez, considerando as zonas urbanas da Nigéria, Ogun (2010) investigou o impacto dos investimentos em infraestrutura na redução da pobreza, utilizando informaçóes para o período 1970-2005 e a metodologia de Vetores Autoregressivos (VAR). Os resultados também confirmam que os investimentos em infraestrutura em geral reduzem a pobreza, mas sugerem que os investimentos em infraestrutura social possuem maior impacto.

Alguns outros estudos existentes na literatura estabeleceram relação entre investimentos em alguns itens de infraestrutura e pobreza, levando em consideração, por exemplo, os setores de transporte e comunicação, confirmando os resultados satisfatórios de alguns trabalhos (Ferreira e Andrade, 2016; Machado e Toma, 2017).

Nesse sentido, considerando os países latino americanos, Durán e Saavedra (2014) evidenciaram o impacto da qualidade da infraestrutura rodoviária, medida pelo total de estradas pavimentadas de cada país, sobre a pobreza. O estudo quantificou o impacto direto da qualidade da infraestrutura sobre a pobreza na regiáo através de um painel com 17 países durante o período 1980-2012. Os resultados demonstraram que a elevação de $1 \%$ no investimento nas rotas pavimentadas diminui em $0.76 \%$ a taxa de pobreza e em $0.20 \%$ a taxa de pobreza extrema. Os autores ainda observaram a existência de grande disparidade na cobertura e qualidade da infraestrutura entre os países da regiáo, particularmente entre zonas urbanas e rurais. Também considerando um país em desenvolvimento, Edriss (2017) analisou especificamente os efeitos dos investimentos nas estradas das áreas rurais do Malawi entre 1994 e 2013 sobre a diminuição da pobreza, confirmando a referida relação.

Para o Brasil, Ponzoni e Fochezatto (2013) analisaram os efeitos dos investimentos em construção civil sobre a redução da pobreza através de um modelo com dados em painel dinâmico para todos os estados durante o período 1985-2008. Os autores concluíram que o referido setor pode gerar empregos de baixa qualificação, proporcionando aos trabalhadores com menor nível de escolaridade maiores salários, o que lhes permitiria sair da linha de pobreza no curto prazo.

Por outro lado, alguns estudos enfatizam os efeitos da infraestrutura social sobre o nível de pobreza. Assim, ao analisar os efeitos dos diferentes tipos de despesas sociais dos governos federal, estadual e municipal sobre a pobreza no Brasil durante o período 1988-2010, Hiromoto (2018) verificou que as políticas macroeconômicas de despesa social contribuem para redução da pobreza. Nesse caso, as despesas em saúde e saneamento apresentaram maior impacto na diminuição da a pobreza, seguidas pelas transferências de renda do governo a nível federal. Nessa mesma linha, 
Cruz et al. (2010) concluíram que o capital social é uma ferramenta efetiva para aumentar a renda per capita e o dinamismo do mercado laboral através do aumento da oferta de trabalho, o que pôde ser verificado para os estados brasileiros no período 1995-2008.

Alguns trabalhos analisaram, como o presente estudo, o efeito da infraestrutura pública sobre a pobreza, considerando tanto a infraestrutura econômica como a social. Considerando novamente o Brasil, Araújo et al. (2014), através de um modelo com dados em painel dinâmico para o período 1995-2009, obtiveram resultados consistentes. Os autores concluíram que os investimentos públicos em infraestrutura (transportes, energia e recursos minerais, educação, comunicação e saúde e saneamento) tiveram impacto significativo na redução da pobreza. Resultado similar foi observado por Tabosa et al. (2017), os quais determinaram que as políticas que têm como fim elevar o rendimento médio das famílias e reduzir a desigualdade afetam negativamente a pobreza, sendo o efeito mais acentuado no caso da pobreza extrema.

Por fim, considerando 13 países latino americanos, Peláez et al. (2007) verificaram o efeito dos investimentos em infraestrutura pública sobre a redução da pobreza. Os autores evidenciaram que a elevação de tais investimentos, sejam públicos ou público-privados, reduzem os índices de pobreza da área beneficiada. No entanto, a redução da pobreza não é homogênea devido à distinta eficiência na execução dos investimentos.

\section{Metodologia}

\subsection{Base de dados e variáveis}

Este estudo utiliza informações provenientes de dois organismos internacionais: Comissão Económica para a América Latina e o Caribe (CEPAL) e Banco Mundial (BM), correspondentes a informaçóes sobre infraestruturas econômica e social, além de dados referentes aos níveis de pobreza e pobreza extrema na América Latina.

O método utilizado para definir quem é considerado pobre na amostra tem como base as denominadas linhas de pobreza monetária (linhas de pobreza e pobreza extrema), que estabelecem o custo de satisfação das necessidades básicas alimentares e não alimentares. Este método consiste em mensurar o nível de pobreza através dos rendimentos das famílias dos países da América Latina. A referida metodologia permite a estimação da magnitude da pobreza e pobreza extrema na região, assim como sua evolução nos diferentes países ao longo do tempo (CEPAL, 2018a).

Nesse sentido, para cumprir os objetivos da pesquisa, foram considerados os índices de pobreza extrema e pobreza publicados pela Organiza- 
ção das Nações Unidas (ONU). Segundo a ONU, a população mundial que vive com menos de USD $1,90^{1}$ por dia se encontra abaixo da linha de pobreza extrema ou indigência. Já a população mundial que vive com menos de USD 3,20 por dia são considerados pobres não extremos. Cabe ressaltar que levar em consideração ambos os índices é importante, pois possibilita que se compare que tipo de infraestrutura possui maior efeito sobre níveis distintos de pobreza. ${ }^{2}$

Por sua vez, as informaçóes relativas à infraestrutura econômica consideradas no estudo são energia, transportes e comunicação; e aquelas referentes à infraestrutura social são educação e saúde. Com relação aos setores incluídos para caracterizar a infraestrutura econômica, a energia é representada pelo consumo de energia eléctrica ( $\mathrm{kWh}$ per capita), mensurado pela produção das centrais elétricas e das centrais de cogeração menos as perdas ocorridas na transmissão, distribuição e transformação e consumo próprio das unidades de cogeração. Para o setor de transporte, ${ }^{3}$ é utilizada como proxy a porcentagem de passageiros aéreos transportados sobre a populaçáo total em aeronaves, tanto nacionais como internacionais de companhias aéreas registradas no país. O setor de comunicação é representado pelo total de indivíduos que utilizam telefones celulares por cada 100 habitantes.

No que se refere à infraestrutura social, o setor de saúde é representado pelas despesas públicas em saúde como porcentagem do PIB. Por sua vez, o setor educacional tem como proxy as despesas públicas em educaçáo como porcentagem do PIB. Já o desemprego corresponde à taxa de desemprego urbano aberto em função do sexo e dos grupos etários.

Por fim, foram incluídas dummies de países com o intuito de verificar como os países latino americanos se diferenciam quanto ao nível de pobreza e pobreza extrema, tendo como base o Uruguai. Nesse caso, é possível controlar a questáo localizacional dos indivíduos. Ou seja, se o fato de o indivíduo residir em um determinado país, levando em consideração suas características, pode afetar suas chances de ser pobre e extremamente pobre em relação ao país de referência, no caso o Uruguai. Resumidamente, o quadro 1 apresenta todas as variáveis utilizadas nos modelos econométricos com seus respectivos sinais esperados. Cabe salientar que o critério de seleção das variáveis explicativas foi a literatura que concerne o tema.

Antes de aplicar a metodologia de dados em painel, inicialmente foi necessário tratar os dados para completar os anos faltantes da série tem-

${ }^{1}$ USD: código internacional do dólar dos EE.UU.

${ }^{2}$ Definições extraídas da base de dados da CEPALSTAT, CEPAL (2019).

${ }^{3}$ Esta proxy é utilizada devido à escassez de dados relativos a outro modal de transporte para o conjunto de países considerados na amostra. 
poral considerada. O método utilizado para este fim foi a interpolaçáo e extrapolação linear. Posteriormente, foi possível utilizar os dados aplicados nos modelos econométricos através do pacote estatístico STATA 14 (Stata, 2015).

\section{Quadro 1 \\ Variáveis selecionadas para estimaçáo dos modelos econométricos e seus sinais esperados}

\begin{tabular}{ll}
\hline \multicolumn{1}{c}{ Variáveis } & \multicolumn{1}{c}{ Sinal esperado } \\
\hline Pobreza & Variável dependente \\
\hline Energia & $\begin{array}{l}\text { Espera-se relaçáo negativa entre acesso à infraestrutura de } \\
\text { energia e pobreza (Ali e Pernia, 2003) }\end{array}$ \\
\hline Transporte & $\begin{array}{l}\text { Espera-se relação negativa entre acesso à infraestrutura de } \\
\text { transportes e pobreza (Edriss, 2017) }\end{array}$ \\
\hline Comunicação & $\begin{array}{l}\text { Espera-se relaçáo negativa entre acesso a infraestrutura de } \\
\text { comunicaçáo e pobreza (Aparicio et al., 2011) }\end{array}$ \\
\hline Saúde & $\begin{array}{l}\text { Espera-se relação negativa entre gastos com infraestrutura } \\
\text { em saúde e pobreza (Cruz et al., 2017) }\end{array}$ \\
\hline Educação & $\begin{array}{l}\text { Espera-se relação negativa entre gastos com infraestrutura } \\
\text { educacional e pobreza (Hiromoto, 2018) }\end{array}$ \\
\hline Desemprego & $\begin{array}{l}\text { Espera-se relaçáo positiva entre desemprego e pobreza } \\
\text { (Ferreira e Andrade, 2016) }\end{array}$ \\
\hline Dummies que representam & $\begin{array}{l}\text { D1 (Argentina), D2 (Bolívia), D3 (Brasil), D4 (Chile), D5 } \\
\text { (Colômbia), D6 (Costa Rica), D7 (Equador), D8 (El } \\
\text { os países }\end{array}$ \\
$\begin{array}{l}\text { Salvador), D9 (Honduras), D10 (México), D11 (Panamá), } \\
\text { D12 (Paraguai), D13 (Peru), D14 (República Domini- } \\
\text { cana), D15 (Uruguai); sendo D15 a base }\end{array}$ \\
\hline
\end{tabular}

Fonte: elaboração própria com base na literatura.

\subsection{Modelo econométrico}

Os dados em painel também conhecidos como combinação de dados de séries de tempo e de corte transversal têm várias vantagens, tais como controle sobre a heterogeneidade individual, mais variabilidade, menos colinearidade entre as variáveis, mais graus de liberdade e maior eficiência, melhor capacidade de identificar e medir efeitos que não são detectáveis em dados puros de seção cruzada ou de séries temporais, assim como melhor capacidade de análise em comportamentos mais complicados.

Além disso, muitas relaçóes econômicas são de natureza dinâmica e, logo, o modelo aqui utilizado permite ao pesquisador compreender melhor 
a dinâmica do ajuste, o que é possível através da inclusão da variável explicativa que corresponde à dependente defasada (Baltagi, 2005). Assim, tendo em vista o objetivo central do estudo, que é o de analisar o impacto dos investimentos em infraestrutura pública (econômica e social) sobre a pobreza, o modelo econométrico considerado para o período 1996-2016 pode ser definido da seguinte forma:

$$
\begin{aligned}
& \ln \left(\text { Pob }_{i t}\right)=\beta_{0}+\beta_{1} \ln \left(\text { Pob }_{i t-1}\right)+\beta_{2} \ln \left(\text { Ener }_{i t}\right)+\beta_{3} \ln \left(\text { Transpopu }_{i t}\right)+ \\
& \beta_{4} \ln \left(\text { Com }_{i t}\right)+\beta_{5} \ln \left(\text { Saude }_{i t}\right)+\beta_{6} \ln \left(\text { Educ }_{i t}\right)+\beta_{7} \ln \left(\text { Desemp }_{i t}\right)+U_{i t}(1)
\end{aligned}
$$

Onde $\ln P o b_{i t}$ representa o índice de pobreza de acordo com a linha de pobreza (ou seja, pobext é a proporção de pobreza extrema ou indigência; e pob a proporção de pobreza). Entre os parâmetros $\beta_{2 i}$ a $\beta_{7 i}$ tem-se a representação das infraestruturas econômica e social, assim como o desemprego, medidas por: $\ln E n e r_{i t}$, energia; $\ln$ Transpopu $_{i t}$, transporte; $\ln$ Com $_{i t}$, comunicação; Saude $_{i t}$, despesas em saúde; $\ln E d u c_{i t}$, despesas em educação; $\ln$ Desem $_{i \ell}$, taxa de desemprego; e $u_{i t}$ é o termo de erro idiossincrático.

Os subíndices i e t referem-se respectivamente aos países da regiáo $i=1$, 2... 15, que são: 1: Argentina, 2: Bolívia, 3: Brasil, 4: Chile, 5: Colômbia, 6: Costa Rica; 7: Equador, 8: El Salvador, 9: Honduras, 10: México, 11: Panamá, 12: Paraguai, 13: Peru, 14: República Dominicana, 15: Uruguai e o período de 1996 a 2016 é representado por $t=1,2 \ldots 21$.

A especificação do modelo (1) baseia-se no pressuposto supracitado de que a pobreza do período anterior tende a influenciar a dinâmica da pobreza atual. Isso justifica a presença da variável dependente defasada em um período $\ln \left(P o b i_{t-1}\right)$ como variável explicativa (Baltagi, 2005).

A relação entre as variáveis que denotam a infraestrutura pública (infraestruturas econômica e social) e as variáveis dependentes (pobreza e pobreza extrema) é potencialmente endógena. Então, a presença de $P o b_{i t-1}$ como variável explicativa na equação (1) pode dar origem ao problema de endogeneidade. Nesse caso, as estimativas por Mínimos Quadrados Ordinários (MQO) tendem a ser enviesadas e inconsistentes, sobrestimando o coeficiente da variável estimada. Para corrigir tal problema, além de possibilitar a inclusão da referida relação dinâmica entre as variáveis, deve ser aplicada a transformação do modelo em primeira diferença e proceder a estimativa pelo Método Generalizado de Momentos (GMM), a partir da minimização das condiçóes de momentos da distribuição. Desse modo, a equação (1) passa a ser a seguinte: ${ }^{4}$ 
$\ln \left(\right.$ Pob $\left._{i t}\right)=\beta_{1} \Delta \ln \left(\right.$ Pob $\left._{i t}-1\right)+\beta_{2} \Delta \ln \left(\right.$ Ener $\left._{i t}\right)+\beta_{3} \Delta \ln \left(\right.$ Transpopu $\left._{i t}\right)+\beta_{4} \Delta$
$\ln \left(\right.$ Com $\left._{i t}\right)+\beta_{5} \Delta \ln \left(\right.$ Saude $\left._{i t}\right)+\beta_{6} \Delta \ln \left(\right.$ Educ $\left._{i t}\right)+\beta_{7} \Delta \ln \left(\right.$ Desemp $\left._{i t}\right)+\Delta U_{i t}(2)$

Onde $\Delta$ é um operador de diferenças e pela construção da equação (2), $\Delta \ln \left(P o b i_{t-1}\right)$ e $\Delta U_{i t}$ são correlacionados e a endogeneidade ainda persiste. Dessa forma, torna-se necessário o uso de algum instrumento para $\Delta \ln \left(\right.$ Pobi $\left._{t-1}\right)$.

No entanto, Arellano e Bover (1995) e Blundell e Bond (1998) explicam que esses instrumentos são fracos quando as variáveis, dependentes e explicativas, apresentam marcada persistência; quando a variância relativa dos efeitos fixos aumenta; ou quando ocorrem ambos os eventos. Nesse caso, o estimador é inconsistente e tendencioso e como solução os autores recomendam a estimativa de um sistema que combine o conjunto de equações em diferenças - equação (2) - com o conjunto de equaçóes em nível -equação (1) - conhecido como método GMM para sistemas (System-GMM).

Antes de estimar o modelo com dados em painel dinâmico, procedeu-se à verificação da existência de endogeneidade. Posteriormente, foram necessários alguns testes para analisar a consistência das estimativas. Em seguida, realiza-se o teste de Sargan para verificar a validade dos instrumentos utilizados pelo método System-GMM.

\section{Resultados e discussão}

\subsection{Análise descritiva}

Nesta subseção são apresentadas as estatísticas descritivas dos indicadores de pobreza e pobreza extrema dos países analisados da América Latina no ano de 2016, mais recente na amostra; e posteriormente sua evolução na regiāo durante as últimas duas décadas, período 1996-2015.

O gráfico 1 apresenta os níveis de pobreza dos países da regiáo em estudo. É possível observar que até 2016 os países que apresentam menores níveis de pobreza são Uruguai, com $0.55 \%$ da população total; seguido do Chile, com 1.21\%; e por último Argentina, com 2.4\%. Por sua vez, os países que apresentaram maiores níveis de pobreza para o mesmo período são Honduras, com $30.03 \%$ da população total; vindo em seguida a Bolívia, com 12.63\%; e finalmente a Colômbia, com 1.83\%.

No gráfico 2, verificam-se os níveis de pobreza extrema ou indigência dos países latino americanos analisados no ano de 2016. Existe uma tendência em relação aos dois indicadores de pobreza, nos quais os países 
que apresentaram menores níveis de pobreza também possuem baixos níveis de indigência, sendo estes Uruguai, com $0.06 \%$ da população total; seguido da Argentina, com $0.58 \%$; posteriormente Chile, com $0.62 \%$.

Gráfico 1

Porcentagem da populaçáo pobre na América Latina (menos de USD 3,20) 2016

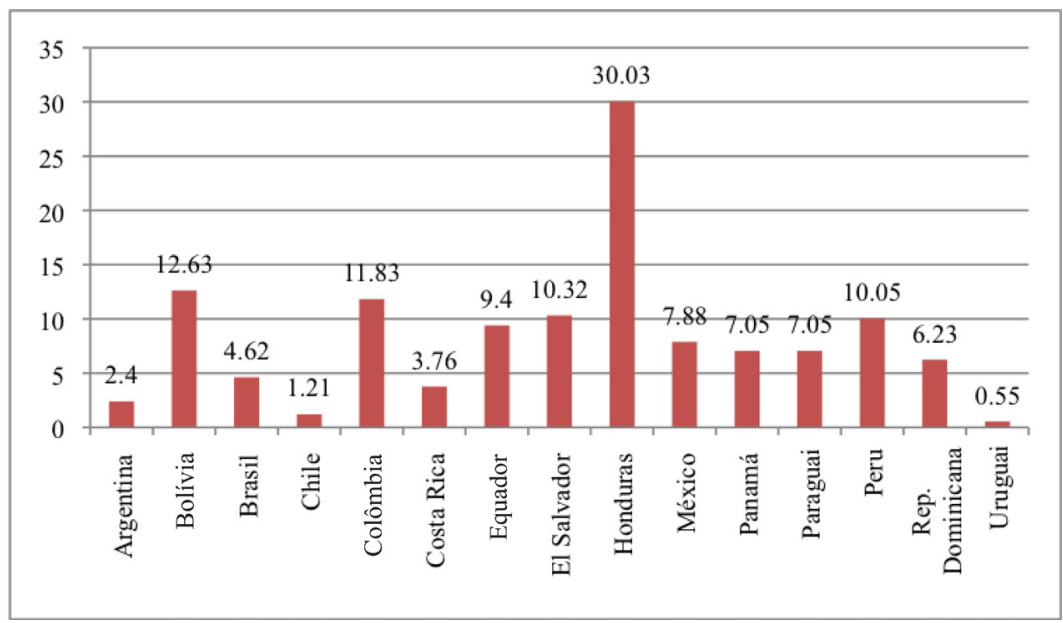

Fonte: elaboração própria com base nos dados da CEPAL (2016).

\section{Gráfico 2}

Porcentagem da populaçáo em extrema pobreza na América Latina (menos de USD 1,90) 2016

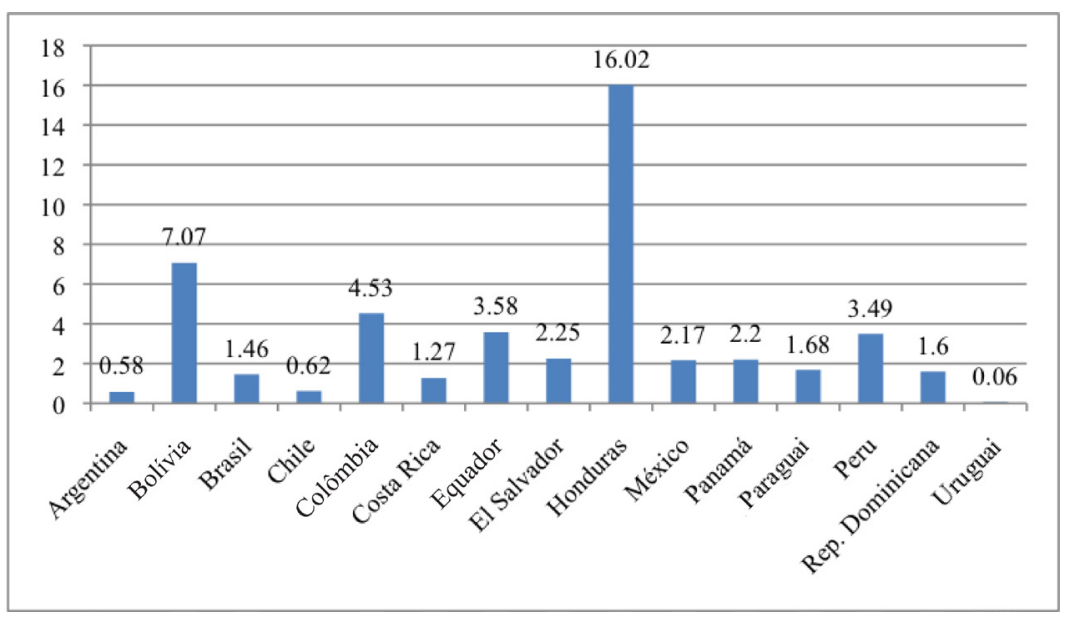

Fonte: elaboraçáo própria com base nos dados da CEPAL (2016). 
Por outro lado, os países com elevados níveis de indigência também apresentam a mesma tendência: Honduras, com 16.02\%; Bolívia, com 7.07\%, e por último Colômbia, com 4.53\%.

O gráfico 3 apresenta, respectivamente, a evoluçáo das porcentagens da população pobre e pobre extrema (indigente) na América Latina durante o período 1996-2015, período de duas décadas. Observa-se tendência descendente em ambos os indicadores de pobreza na região, sendo esta explicada por vários fatores. Além do contexto histórico e político que condicionou os investimentos públicos em infraestrutura, vide a primeira seção do presente estudo, no Chile, El Salvador e República Dominicana, o aumento nos rendimentos do trabalho foi sua principal causa. Por outro lado, na Costa Rica, Panamá e Uruguai, as transferências governamentais para os lares permitiram às famílias em condição de vulnerabilidade sair da linha de pobreza (CEPAL, 2019).

\section{Gráfico 3}

\section{Evoluçáo da porcentagem da populaçáo pobre e pobre extrema na América Latina, no período 1996-2015}

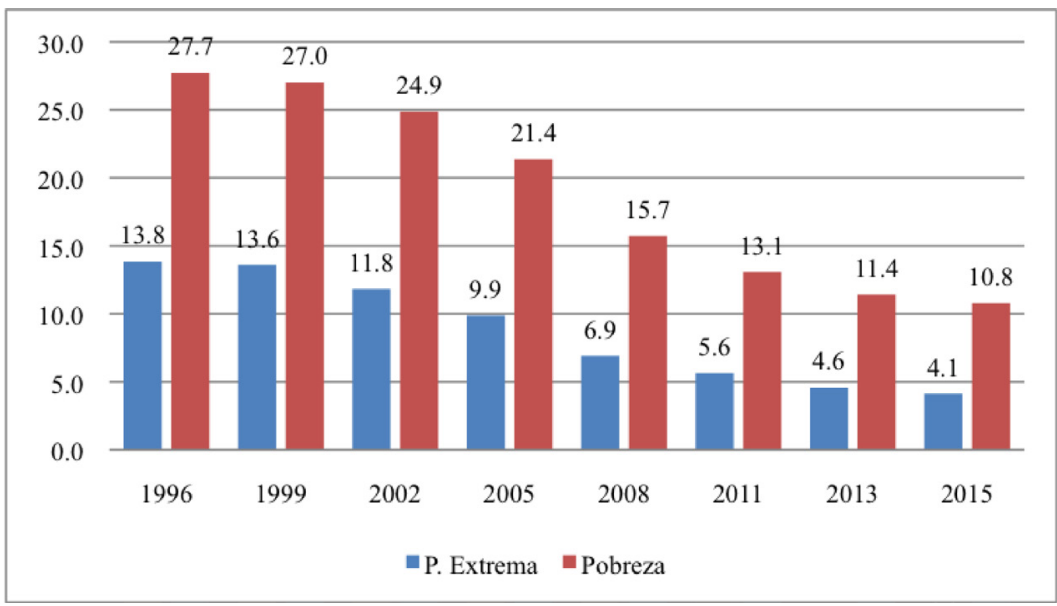

Fonte: elaboração própria com base nos dados da CEPAL (1996-2015).

Analisando-se a evolução da pobreza por subperíodos da amostra, em geral, sua diminuição durante o período 1990-1999 deveu-se às oscilaçôes do crescimento econômico nos países analisados, como descrito na supracitada primeira seção desse trabalho. Por sua vez, no período 20022012, a região também apresentou redução da pobreza e indigência. Estes resultados tiveram como principais causas o contexto econômico favorável, as melhorias no mercado de trabalho, a implementação de programas 
sociais destinados à inclusão social dos indivíduos mais vulneráveis, além da redução do desemprego e aumento do preço das matérias-primas.

No entanto, entre 2012 e 2013 houve relativa estagnação do processo de redução da pobreza como consequência da diminuição no ritmo de crescimento econômico mundial, do fim do 'superciclo' dos produtos básicos, da maior pressão inflacionária e da diminuição da capacidade de geração e formalizaçáo do emprego. Apesar da ligeira recuperaçáo econômica em 2014, a procura agregada dos países da América Latina e o Caribe diminuiu devido ao baixo crescimento das economias desenvolvidas e a desaceleração das economias emergentes, em especial da China (CEPAL, 2016).

Não obstante a redução dos índices de pobreza na América Latina, os níveis ainda são relativamente elevados até 2015. A população da América Latina que sobrevive com menos de USD 1,90 por dia corresponde a $4.1 \%$ do total e $10.8 \%$ da população sobrevive com menos de 3,20 por dia.

De forma geral, segundo as estimativas atualizadas da CEPAL sobre pobreza e indigência, os dois fenômenos diminuíram consideravelmente no agregado regional, embora a um ritmo cada vez menor no período entre 2002 e 2014. Já entre 2015 e 2016, as estatísticas revelaram um aumento nos níveis gerais de pobreza e indigência regionais (América Latina como um todo), apesar de estes continuarem diminuindo na maioria dos países (CEPAL, 2018b).

\subsection{Resultados econométricos}

Nesta seção são apresentados e discutidos os resultados obtidos através da estimação do modelo com dados em painel dinâmico. Os resultados da estimativa dos parâmetros das equaçôes (1) com o auxílio da equação (2) são apresentados na tabela 1 .

Inicialmente, através dos testes verificou-se endogeneidade das variáveis educação (Educit) e desemprego (Desemit) com as variáveis dependentes. Assim, os resultados indicam que ambas variáveis são endógenas no modelo. Cavalcanti e Santos (2007), ao analisar o impacto das despesas públicas sobre a pobreza brasileira, utilizando como proxy de educação a média dos anos de estudo para indivíduos com 25 anos de idade ou mais, também verificaram a existência de endogeneidade. Além deste trabalho, Jiménez e Alvarado (2018), em seu estudo sobre o efeito da produtividade laboral na pobreza no Equador, também mencionam a existência de relaçáo endógena entre a taxa de pobreza e a média do capital humano regional.

Por sua vez, os testes realizados no modelo revelaram que as propriedades estatísticas são satisfeitas. A endogeneidade das variáveis valida a 
682 A. D. Cuenca López e E. Camargos Teixeira: Efeitos dos investimentos em infraestrutura...

\section{Tabela 1}

\section{Efeitos da infraestrutura pública na pobreza extrema e pobreza na América Latina}

\begin{tabular}{|c|c|c|c|c|}
\hline \multirow[t]{2}{*}{ Variáveis } & \multicolumn{2}{|c|}{ Pobreza } & \multicolumn{2}{|c|}{ Extrema Pobreza } \\
\hline & Coeficiente & P-valor & Coeficiente & P-valor \\
\hline $\ln \left(\right.$ Pobi $\left._{t-1}\right)$ & $0.7923^{* * *}$ & 0.0000 & $0.6734^{* * *}$ & 0.0000 \\
\hline $\ln \left(\right.$ Ener $\left._{i t}\right)$ & $-0.4299^{* * *}$ & 0.0000 & $-0.6084^{* * *}$ & 0.0000 \\
\hline $\ln \left(\right.$ Transpopu $\left.u_{i t}\right)$ & $-0.0174^{\mathrm{NS}}$ & 0.4700 & $-0.0852^{* *}$ & 0.0120 \\
\hline $\ln \left(\operatorname{Com}_{i t}\right)$ & $-0.0112^{\mathrm{NS}}$ & 0.3110 & $-0.0389^{* *}$ & 0.0140 \\
\hline $\ln \left(\right.$ Saude $\left._{i t}\right)$ & $0.0312^{\mathrm{NS}}$ & 0.5630 & $-0.0360^{\mathrm{NS}}$ & 0.6450 \\
\hline $\ln \left(E d u c_{i t}\right)$ & $-0.0790^{*}$ & 0.0650 & $-0.1272^{* *}$ & 0.0380 \\
\hline $\ln \left(\right.$ Desem $\left._{i t}\right)$ & $0.1081^{* * *}$ & 0.0010 & $0.1007^{* *}$ & 0.0250 \\
\hline D1-Argentina & $0.3870^{* * *}$ & 0.0000 & $0.9589^{* * *}$ & 0.0000 \\
\hline D2-Bolívia & $0.0355^{\mathrm{NS}}$ & 0.8370 & $0.5944^{* *}$ & 0.0150 \\
\hline D3-Brasil & $0.4415^{* * *}$ & 0.0000 & $1.0437^{* * *}$ & 0.0000 \\
\hline D4-Chile & $0.4419^{* * *}$ & 0.0010 & $1.2353^{* * *}$ & 0.0000 \\
\hline D5-Colômbia & $0.3117^{* *}$ & 0.0120 & $0.7651^{* * *}$ & 0.0000 \\
\hline D6-Costa Rica & $0.2845^{* * *}$ & 0.0050 & $0.8368^{* *}$ & 0.0000 \\
\hline D7-Equador & $0.1970^{\mathrm{NS}}$ & 0.1070 & $0.6664^{* * *}$ & 0.0000 \\
\hline D8-El Salvador & $0.0948^{\mathrm{NS}}$ & 0.5060 & $0.5656^{* * *}$ & 0.0050 \\
\hline D9-Honduras & $0.0218^{\mathrm{NS}}$ & 0.8790 & $0.5533^{* * *}$ & 0.0070 \\
\hline D10-México & $0.6413^{* * *}$ & 0.0000 & $1.1079^{* * *}$ & 0.0000 \\
\hline D11-Panamá & $0.3417^{* * *}$ & 0.0050 & $1.0362^{* * *}$ & 0.0000 \\
\hline D12-Paraguai & $0.1674^{\mathrm{NS}}$ & 0.1220 & $0.5222^{* * *}$ & 0.0010 \\
\hline D13-Peru & $0.2348^{*}$ & 0.0680 & $0.7187^{* * *}$ & 0.0000 \\
\hline D14-Rep. Dominicana & $0.2118^{*}$ & 0.0700 & $0.2266^{\mathrm{NS}}$ & 0.1670 \\
\hline Constante & $3.2403^{* * *}$ & 0.0000 & $4.5446^{* * *}$ & 00000 \\
\hline Teste de Sargan & & 0.2268 & & 0.5565 \\
\hline Observaçôes & & & & \\
\hline
\end{tabular}

Nota: * significativo a $10 \%$; ${ }^{* *}$ significativo a $5 \%$; *** significativo a $1 \%$; NS não significativo. Fonte: Elaboração própria, com base em STATA (2015) e dados da CEPAL (1995-2016). 
utilização do Método dos Momentos Generalizados (Generalized Moments Method-GMM). Cabe ainda ressaltar que os resultados do teste de Sargan, que podem ser observados na tabela 1, confirmam que os instrumentos utilizados no modelo são válidos, o que possibilitou a obtenção de estimadores consistentes mediante o método utilizado.

Como as variáveis utilizadas, com exceção das dummies que representam os países, foram transformadas em logaritmo natural, tem-se um modelo de duplo logaritmo. Portanto, a inclinaçáo dos coeficientes estimados representa suas respectivas elasticidades. No que se refere aos coeficientes estimados para as variáveis correspondentes a infraestrutura econômica, foi possível observar que todas são significativas para o modelo cuja variável dependente é a pobreza extrema. Por sua vez, para o modelo que considera a pobreza, apenas a variável que denota o consumo de energia elétrica foi significativa.

Assim, analisando-se o efeito da infraestrutura econômica no que diz respeito à energia, representada pela capacidade instalada para a produção de 1 quilowatt ( $\mathrm{kW}$ ) per capita, o aumento do investimento em 1 ponto percentual neste setor reduz a pobreza em $0.43 \%$ e a pobreza extrema em $0.61 \%$. Nesse sentido, o investimento em infraestrutura energética eleva a demanda por trabalho, impactando diretamente sobre os rendimentos e consequente redução da pobreza (Cruz et al., 2010).

No caso da infraestrutura de transportes, se o número de passageiros transportados via aérea aumenta 1\%, a pobreza extrema diminui em $0.09 \%$. A CEPAL (2016) menciona que existem zonas montanhosas e de difícil acesso na América Latina, justificando a importância dos aeroportos. Nesse sentido, os investimentos em transportes são importantes para o crescimento econômico e redução das desigualdades regionais na ALC (Costa et al., 2016). Especificamente, a melhoria na infraestrutura de transporte permite mais acesso às diferentes regiōes e mercados, o que reduz os custos de transporte internos, tanto para a indústria como para os indivíduos da regiáo, o que impulsiona o desenvolvimento (Muñoz, 2016).

Em relação ao setor de comunicaçôes, a pobreza extrema diminui em $0.04 \%$ quando os investimentos neste setor aumentam em $1 \%$. Cavalcanti e Santos (2007) ressaltam que a comunicação eleva a produtividade dos fatores privados e reduz os custos por unidade de entrada das empresas, conectando-as de forma mais eficiente e gerando maiores taxas de lucros.

Com relação aos coeficientes das variáveis que representam a infraestrutura social, a educação é estatisticamente significativa nos dois modelos e apresenta sinais esperados. Por sua vez, no que diz respeito à variável de saúde, esta não apresentou significância estatística. Assim, os coeficientes estimados indicam que o aumento de um ponto porcentual nas despesas públicas em educação reduze a pobreza em $0.08 \%$ e a indigência 
em $0.13 \%$ nos países da regiáo. Rodrigues (2007) observou que os trabalhadores brasileiros mais qualificados têm mais acesso a postos de trabalho melhor remunerados, além do fato de que a proporção de pobres declina à medida que aumenta o nível educacional dos indivíduos.

De forma resumida, observando-se os resultados centrais do estudo, percebe-se que a pobreza extrema é mais sensível em relação às variaçóes na infraestrutura pública, tanto econômica quanto social, em relação à pobreza. Somente a infraestrutura de saúde náo a impactou e todos os coeficientes estimados em termos de infraestrutura pública foram superiores ao modelo de pobreza. No que tange este último, somente a infraestrutura de energia (econômica) e educaçáo (social) tiveram efeito estatisticamente significativo sobre a mesma. Dessa forma, pode-se concluir que os investimentos em infraestrutura econômica e social impactarão de forma proeminente sobre a população mais miserável, o que de antemão justifica seu planejamento e implementação.

Além desse importante resultado, conforme a tabela 1 confirma-se a hipótese dinâmica da pobreza, pois a variável de $\ln \left(\right.$ Pobi $\left._{t-1}\right)$ foi estatisticamente significativa a $1 \%$, tanto para o modelo de pobreza como para o de extrema pobreza. Estes resultados confirmam a persistência no tempo dos níveis de pobreza, o que indica que a pobreza passada afeta a pobreza presente. Os mesmos resultados foram obtidos por Aparicio et al. (2011), Araújo et al. (2014) e Costa et al. (2016).

Os referidos resultados indicam que o aumento de $1 \%$ da pobreza no período precedente eleva a pobreza no período posterior em $0.79 \%$. O mesmo resultado pode ser verificado no modelo que considera a pobreza extrema. Nesse último caso, se a indigência do período passado aumentar $1 \%$, haverá elevação da extrema pobreza no próximo período em $0.67 \%$.

Por outro lado, o coeficiente estimado para a variável de desemprego foi estatisticamente significativo e apresentou os sinais esperados. A pobreza e a indigência são elevadas em $0.11 \%$ e $0.10 \%$, respectivamente, quando a taxa de desemprego aumenta em $1 \%$. Este resultado coincide com os resultados encontrados por Marinho et al. (2011), onde o desemprego afeta em maior medida os mais pobres com rendimentos próximos à linha de pobreza.

Finalmente, no que se refere às dummies dos países, observa-se que os coeficientes foram significativos em ambos os modelos na maioria dos países. Seguindo as estatísticas descritivas, considerou-se como país de referência o Uruguai por apresentar menores taxas de pobreza e indigência na região. Os resultados assinalam marcada diferença entre o país de referência (Uruguai) e os outros países analisados. Em consequência, conclui-se que os demais países incluídos na amostra apresentam maiores índices de pobreza e indigência em relação ao país supracitado. 
No trabalho de Durán e Saavedra (2014) referente às estatísticas de pobreza, o Uruguai também é o país que apresenta menor taxa de indigência (porcentagem de pessoas que vivem com menos de USD 2 por dia) com apenas $2.7 \%$ do total da populaçáo; além de menor taxa de pobreza (porcentagem das pessoas que vivem com menos de USD 4 diários), $14.4 \%$ do total da população.

\section{Consideraçóes finais}

A redução da pobreza é um dos Objetivos de Desenvolvimento Sustentável (ODS), promovido pelas Naçôes Unidas (ONU), sendo que uma das soluções propostas, particularmente para a América Latina, se refere ao maior nível de investimentos públicos em infraestrutura. Assim, o objetivo desse estudo foi analisar o efeito dos investimentos em infraestrutura pública (econômica e social) sobre a pobreza e extrema pobreza latino-americana no período 1996-2016. Para tal, utilizou-se a metodologia de dados em painel dinâmico.

Com relação aos resultados, pôde-se constatar a importância dos investimentos em infraestrutura econômica e social como forma de reduzir a pobreza e a extrema pobreza na América Latina. Além disso, os resultados sugerem que a pobreza corresponde a um processo dinâmico e persistente, pois existe um círculo vicioso indicando que a pobreza passada está relacionada com a pobreza presente. Cabe ainda salientar que o desemprego eleva os níveis de pobreza e extrema pobreza, assim como residir no Uruguai diminui as chances de que os indivíduos estejam abaixo das linhas de pobreza e indigência.

Embora os resultados denotem que os investimentos públicos (econômicos e sociais) são primordiais para diminuição da pobreza, particularmente em sua forma extrema, é importante ressaltar a importância da elevação na despesa social média dos países da América Latina, que quase duplicou-se no período 2002-2016.

O supracitado aumento nas despesas sociais constitui-se em um fator fundamental para a expansão das políticas sociais na América Latina, que elevaram a transferência de recursos para as famílias mais pobres, além de propiciar melhorias significativas nos indicadores de inclusão social relacionados a educação, saúde e infraestruturas básicas, apesar da existência de desigualdades na cobertura e qualidade dos serviços.

Finalmente, a metodologia utilizada para estabelecer os indicadores de pobreza corresponde ao método da linha de pobreza monetária, que apenas considera o custo de uma cesta mínima de bens (incluindo os alimentos) e serviços. Por conseguinte, para próximas pesquisas seria conveniente a 
utilizaçáo de outras abordagens, como a da pobreza multidimensional, que considera outros fatores, tais como níveis de educação, saúde, segurança social, habitação e qualidade de vida em geral.

\section{Referências}

Ali, Ifzal e Pernia, Ernesto (2003), "Infrastructure and Poverty Reduction-What is the Connection?”, ERD Policy BriefSeries, núm. 13, Manila, Asian Development Bank, pp. 1-13, <https://www.adb. $\mathrm{org} /$ publications/infrastructure-and-poverty-reduction-whatconnection>, 19 de abril de 2019.

Aparicio, Carlos; Jaramillo, Miguel e San Román, Cristina (2011), "Desarrollo de la infraestructura y reducción de la pobreza: el caso peruano", Lima, Consorcio de Investigación Económica y Social y Universidad del Pacífico, <http://repositorio.minedu. gob.pe/handle/123456789/1310>, 27 de dezembro de 2018.

Araújo, Jair Andrade de; Campelo, Guaracyane e Marinho, Emerson (2014), "O Impacto da Infraestrutura sobre a pobreza para o Brasil”, Anais do XLI Encontro Nacional de Economia, 10-13 de dezembro, Foz do Iguaçu, Brasil.

Arellano, Manuel e Bond, Stephen (1991), "Some Tests of Specification for Panel Data: Monte Carlo Evidence and an Application to Employment Equations", The Review of Economic Studies, 58 (2), Oxford, Oxford University Press, pp. 277-297, doi: https://doi. org/10.2307/2297968

Arellano, Manuel e Bover, Olympia (1995), "Another look at the instrumental variable estimation of error-components models", Journal of Econometrics, 68 (1), North-Holland, Elsevier BV, pp. 29-51, doi: https://doi.org/10.1016/0304-4076(94)01642-D

Baltagi, Badi (2005), "Econometric Analysis of Panel Data, Chichester", West Sussex, John Wiley \& Sons Ltd., <https://himayatullah. weebly.com/uploads/5/3/4/0/53400977/baltagi-econometric-analysis-of-panel-data_himmy.pdf>, 20 de abril de 2019.

Banco Mundial (1994), "Informe sobre el desarrollo mundial 1994: Infraestructura y desarrollo, resumen”, Washington, Banco Mun- 
dial, <https://www.bivica.org/file/view/id/2192>, 2 de janeiro de 2019.

Blundell, Richard e Bond, Stephen (1998), "Initial conditions and moment restrictions in dynamic panel data models", Journal of Econometrics, 87 (1), North-Holland, Elsevier BV, pp. 115-143, doi: https://doi.org/10.1016/S0304-4076(98)00009-8

Bresser-Pereira, Luiz Carlos (2010), "Do antigo ao novo desenvolvimentismo na América Latina", Ensaios em comemoração aos 80 anos de Maria da Conceição Tavares, Rio de Janeiro, Escola de Economia de São Paulo da Fundação Getulio Vargas FGV-EESP, pp. 27-66, <http://www.bresserpereira.org.br/papers/2012/12.Do_ antigo_ao_novo_desenvolvimentismo.pdf $>, 31$ de dezembro de 2018.

Cavalcanti, Pedro e Santos, João (2007), "Um estudo sobre infra-estrutura: impactos produtivos, cooperação público-privado e desempenho recente na América Latina", Rio de Janeiro, Fundação Getúlio Vargas, <http://www.fgv.br/professor/epge/ferreira/InfraAmeLatCepal.pdf>, 20 de abril de 2019.

CEPAL (Comisión Económica para América Latina y el Caribe) (2019), Panorama social de América Latina 2018, Santiago do Chile, CEPAL, <https://repositorio.cepal.org/bitstream/handle/11362/44395/11/S1900051_es.pdf>, 1 de junho de 2019.

CEPAL (Comisión Económica para América Latina y el Caribe) (2018a), Panorama Social de América Latina 2017, Santiago do Chile, CEPAL, <https://repositorio.cepal.org/bitstream/handle/11362/42716/7/S1800002_es.pdf>, 10 de junho de 2019.

CEPAL (Comisión Económica para América Latina y el Caribe) (2018b), Medición de la pobreza por ingresos: actualización metodológica y resultados, Santiago do Chile, CEPAL, <https://www.cepal.org/ es/publicaciones/44314-medicion-la-pobreza-ingresos-actualizacion-metodologica-resultados>, 1 de junho de 2019.

CEPAL (Comisión Económica para América Latina y el Caribe) (2016), Desarrollo social inclusivo. Una nueva generación de politicas para superar la pobreza y reducir la desigualdad en América Latina y el Caribe, Santiago do Chile, CEPAL, <https://www.cepal.org/sites/ 
default/files/events/files/desarrollo_social_inclusivo.pdf>, 9 de abril de 2019.

Costa, Guilherme; De Paula, Humberto e Dantas, Henrique (2016), "Investimentos em infraestrutura de transportes e desigualdades regionais no Brasil: uma análise dos impactos do Programa de Aceleração do Crescimento (PAC)", Revista de Economia Política, 36 (4), São Paulo, Centro de Economía Política, pp. 840-863, doi: https://doi.org/10.1590/0101-31572016v36n04a10

Crespo, Antônio Pedro Albernaz e Gurovitz, Elaine (2002), "A pobreza como um fenômeno multidimensional”, RAE eletrônica, 1 (2), São Paulo, Fundação Getúlio Vargas (FGV), pp. 1-12, doi: https:// doi.org/10.1590/s1676-56482002000200003

Cruz, Aline; Cardoso, Erly e Braga, Marcelo (2010), "Os efeitos dos gastos públicos em infraestrutura e em capital humano no crescimento econômico e na redução da pobreza no Brasil”, Revista Brasileira de Economia, 11 (4), Rio de Janeiro, Fundação Getúlio Vargas e EPGE, Botafogo, pp. 163-185, <http://www.anpec.org. br/revista/vol11/vol11n4p163_185.pdf>, 20 de abril de 2019.

Cuenca-López, Anibal e Torres, Daniel (2020), “Impacto de la inversión en infraestructura sobre la pobreza en Latinoamérica en el período 1996-2016", Población y Desarrollo, 26 (50), San Lorenzo, Universidad Nacional de Asunción, pp. 5-18, doi: https://doi. org/10.18004/pdfce/2076-054x/2020.026.50.005-018

Durán, Eduardo e Saavedra, Eduardo (2014), "Calidad de la infraestructura y pobreza en América Latina”, Ilade, 1 (562), Santiago do Chile, Universidad Alberto Hurtado, pp. 1-21, <http://fen. uahurtado.cl/wp-content/uploads/2010/07/I-306.pdf>, 27 de dezembro de 2018.

Edriss, Abdi-Khalil (2017), "Interfaces between road infrastructure and poverty in Africa: the case of Malawi, 1994-2013", International Journal of Development and Economic Sustainability, 5 (1), Gillingham, European Centre for Research Training and Development, pp. 32-47, <http://www.eajournals.org/wp-content/uploads/ Interfaces-between-Road-Infrastructure-and-Poverty-in-AfricaThe-Case-of-Malawi-1994-2013.pdf>, 19 de abril de 2019. 
Ferreira, Andréa da e Andrade, Jair (2016), "Os gastos públicos e seus impactos na pobreza no Brasil”, Revista Econômica do Nordeste, 47 (3), Fortaleza, Banco do Nordeste do Brasil S.A., pp. 93-108, $<$ https://ren.emnuvens.com.br/ren/article/view/411>, 27 de maio de 2019.

García, José; Bouza, Carlos; Cervantes, Dilia e Sautto, José (2016), Pobreza, desigualdad y violencia en América Latina. Un enfoque metodológico mixto, Barranquilla, Corporación Universitaria Empresarial de Salamanca, <https://rev-inv-ope.univ-paris1.fr/ fileadmin/rev-inv-ope/rideca/Livres/Pobreza_2016.pdf>, 11 de fevereiro de 2020 .

Hiromoto, Martha (2018), "Análise do efeito do gasto social dos governos federal, estadual e municipal sobre a pobreza no Brasil - 1988 a 2010", Pesquisa e planejamento económico, 48 (1), Rio de Janeiro, Instituto de Pesquisa Econômica Aplicada, pp. 71-102, <https:// www.researchgate.net/publication/326812230_ANALISE_DO_ EFEITO_DO_GASTO_SOCIAL_DOS_GOVERNOS_FEDERAL_ESTADUAL_E_MUNICIPAL_SOBRE_A_POBREZA_ NO_BRASIL_-_1988_A_2010>, 19 de abril de 2019.

Jiménez, Jackeline e Alvarado, Rafael (2018), "Efecto de la productividad laboral y del capital humano en la pobreza regional en Ecuador", Journal of Regional Research, 40 (1), Alcalá de Henares, Asociación Española de Ciencia Regional, pp. 141-165, <https://investigacionesregionales.org/wp-content/uploads/sites/3/2018/06/6.Jimenez.pdf>, 19 de abril de 2019.

Kogan, Jorge e Bondorevsky, Diego (2016), "La infraestructura en el desarrollo de América Latina”, Economía y Desarrollo, 156 (1), La Habana, Universidad de La Habana, pp. 168-186, <https:/www. redalyc.org/articulo.oa?id=4255/425547537012>, 23 de junho de 2020.

Machado, Roberto e Toma, Hiroshi (2017), "Crecimiento económico e infraestructura de transportes y comunicaciones en el Perú", Economía, 40 (79), Lima, Pontificia Universidad Católica del Perú (PUCP), Departamento de Economía, pp. 9-46, doi: https://doi. org/10.18800/economia.201701.001

Marinho, Emerson; Linhares, Fabricio e Campelo, Guaracyane (2011), "Os programas de transferência de renda do governo impactam 
a pobreza no Brasil?”, Revista Brasileira de Economia, 65 (3), Rio de Janeiro, Fundação Getúlio Vargas, pp. 267-288, doi: https:// doi.org/10.1590/s0034-71402011000300003

Muñoz, Pablo (2016), "Relación entre inversión en infraestructura de transporte y desarrollo económico", tesis de maestría, Universidad EAFIT, Medellín, <https://repository.eafit.edu.co/bitstream/ handle/10784/12085/Pablo_MunozVallejo_2016.pdf?sequence $=2>, 27$ de dezembro de 2018 .

Ogun, Taiwo Peace (2010), "Infrastructure and poverty reduction: Implications for urban development in Nigeria", Urban Forum, 21 (3), Helsinki, United Nations University World Institute for Development Economics Research, pp. 249-266, doi: https://doi. org/10.1007/s12132-010-9091-8

Peláez Ponce, Ana Victoria; Vargas, Cinthya Pastor; Ríos, Cynthia González; Saavedra, Eduardo; Castillo, Fernando Candia; Vizcarra, José Luis Evia; Neri, Marcelo; Sour, Laura; Torrado, Mónica Parra; Jorba, Luis Mesalles; González, Marino; Bengochea, Pablo Martínez; Celis, Rafael; Moya, Ramiro; Oleas, Sebastián; Andrade, Thompson (2007), "Inversión en Infraestructura Pública y Reducción de la Pobreza en América Latina”, Rio de Janeiro, / Konrad Adenauer Stiftung/, <https://www.kas.de/c/document_ library/get_file? uuid $=$ ad 6 eb $767-6$ bad-0c8a-cb039644c1e5cb31\&groupId=252038>, 27 de setembro de 2018 .

Perrotti, Daniel e Sánchez, Ricardo (2012), "La brecha de infraestructura en América Latina y el Caribe”, Concepto Logístico, núm. 1, Ciudad Autónoma de Buenos Aires, Asociación Argentina de Logística Empresaria, pp. 7-21, <http://www.conceptologistico. com/01/Concepto $\% 20$ Logistico $\% 20$ Numero $\% 20001 \% 20$ vista $\% 20$ en $\% 20$ dobles $\% 20$ paginas $\% 20$ en $\% 20$ baja.pdf>, 27 de dezembro de 2018.

Ponzoni, Cristiano e Fochezatto, Adelar (2013), "Crescimento pró-pobre nos estados brasileiros: análise da contribuição da construção civil usando um modelo de dados em painel dinâmico, 1985-2008”, Economia Aplicada, 17 (3), São Paulo, Universidade de São Paulo (USP), pp. 243-266, doi: https://doi.org/10.1590/S141380502013000300002 
Raihan, Selim (2011), "Infrastructure and Growth and Poverty in Bangladesh", Munich Personal RePEc Archive, South Asian Network on Economic Modeling (SANEM), Dhaka, Department of Economics, University of Dhaka, pp. 1-37, <https://mpra.ub.unimuenchen.de/37882/3/MPRA_paper_37882.pdf>, 19 de abril de 2019.

Rego, José (2014), “Uma interpretação do novo desenvolvimentismo a partir da conjuntura econômica da América Latina", Documentos de Proyecto, núm. 598, Santiago do Chile, Naciones Unidas, Comisión Económica para América Latina y el Caribe (CEPAL), <https://repositorio.cepal.org/bitstream/handle/11362/36712/1/ S2014191_pt.pdf>, 21 de junho de 2020.

Rodrigues, Sonia (2007), Pobreza no Brasil: afinal, de que se trata?, São Paulo, Fundação Getúlio Vargas.

Sánchez, Ricardo; Lardé, Jeannette; Chauvet, Pablo e Jaimurzina, Azhar (2017), "Inversiones en infraestructura en América Latina. Tendencias, brechas y oportunidades", Serie Recursos Naturales e Infraestructura, núm. 187, Santiago do Chile, CEPAL, pp. 1-94. $<$ https://repositorio.cepal.org/bitstream/handle/11362/43134/ S1700926_es.pdf?sequence=1\&isAllowed=y>, 27 de dezembro de 2018.

Serebrisky, Tomás; Suárez-Alemán, Ancor; Margot, Diego e Ramirez, Maria Cecilia (2015), Financiamiento de la infraestructura en América Latina y el Caribe: ¿Cómo, cuánto y quién?, Washington, D.C., Banco Interamericano de Desarrollo, <https://publications. iadb.org/es/publicacion/17044/financiamiento-de-la-infraestructura-en-america-latina-y-el-caribe-como-cuanto-y>, 21 de junho de 2020 .

Stata (2015), "Statistics/Data Analysis, version 14.0", Texas, StataCorp Lp-Stata Press Publication.

Tabosa, Francisco; Castelar, Pablo e Irffi, Guilherme (2017), "Brasil, 1981-2013: efectos del crecimiento económico y de la desigualdad de los ingresos en la pobreza", Revista de la CEPAL, núm. 120, New York, United Nations Publications, pp. 163-180, doi: https://doi.org/10.18356/ab3faedf-es 
Torrisi, Gianpiero (2009), "Public Infrastructure: definition, classification and measurement issues", Economics, Management and Financial Markets, 4 (3), New York, Addleton Academic Publishers, doi: https://doi.org/10.1073/pnas.0703993104

Recebido: 17 de fevereiro de 2020. Encaminhado: 15 de junho de 2020. Aceito: 7 de julho de 2020.

Anibal David Cuenca López. Mestre em Economia pela Universidade Federal de Viçosa (UFV). Atualmente doutorando em Economia Doméstica pela Universidade Federal de Viçosa. Tem experiência na área de economia, com ênfase em métodos e modelos matemáticos, econométricos e estatísticos. Entre suas últimas publicações destacam-se, em coautoria: "Impacto de la inversión en infraestructura sobre la pobreza en Latinoamérica en el período 1996-2016”, Población y Desarrollo, 26 (50), San Lorenzo, pp. 5-18 (2020).

Evandro Camargos Teixeira. Doutor em Economia Aplicada pela Escola Superior de Agricultura "Luiz Queiroz" da Universidade de Sáo Paulo (ESALQ/USP). Atualmente é Professor Associado I do Departamento de Economia da Universidade Federal de Viçosa (UFV). As linhas de investigação referem-se a desenvolvimento econômico, teoria econômica e economia do bem-estar social. Entre suas últimas publicaçóes destacamse, em coautoria: "Mensuração da Pobreza Multidimensional Rural nas Mesorregióes Norte e Jequitinhonha de Minas Gerais", Revista de Economia e Sociologia Rural, 57 (1), Brasília, Sociedade Brasileira de Economia e Sociologia Rural, pp. 161-180 (2019); "Existe fuga de cérebros no Estado de Minas Gerais?, Revista de Economia, 40 (72), Curitiba, Universidade Federal do Paraná, pp. 193-213 (2019); e "La competitividad y sus factores determinantes: un análisis sistémico para países en desarrollo", Revista CEPAL, núm. 129, Santiago de Chile, Organización de las Naciones Unidas, CEPAL, pp. 7-27 (2019). 